The role of medical students' training and community placement as a tool to enhance medical education in Canada

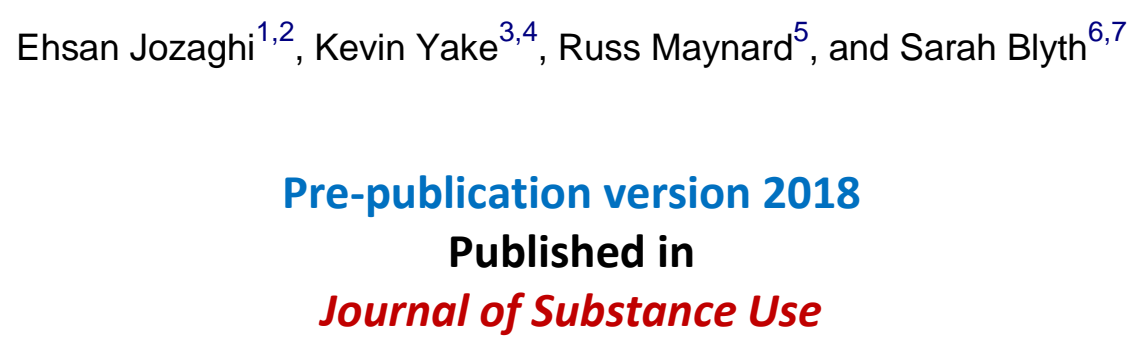

To link to this article: https://doi.org/10.1080/14659891.2018.1510051

1. The British Columbia Centre for Disease Control, Vancouver, B.C., Canada

2. The School of Population and Public Health, University of British Columbia, Vancouver, B.C., Canada

3. Vancouver Area Network of Drug Users, Vancouver, B.C., Canada

4. The Western Aboriginal Harm Reduction Society, Vancouver, B.C., Canada

5. PHS Community Services Society, Vancouver, B.C., Canada

6. Overdose Prevention Society, Vancouver, B.C., Canada

7. Downtown Eastside Street Market Society, Vancouver, B.C., Canada

\title{
Acknowledgments
}

We would like to thank Caimen Yen for editorial assistance. Also thanks to the board members of Vancouver Area Network of Drug Users for reading the draft and appointing an author to work on this letter. Finally, we would like to acknowledge the anonymous reviewers who improved the quality of this manuscript.

\section{Disclosure of potential conflicts of interest}

The views expressed by EJ, KY, RM and SB in this letter are those of the authors, and they may not necessarily express the views of the Canadian Institute of Health Research (CIHR), Ottawa, Ontario or the British Columbia Centre for Disease Control (BCCDC), Vancouver, British Columbia. The CIHR and the BCCDC had no influence on the direction, scope, opinion, view point or the writing of this letter.

\section{Funding}

The contribution by EJ was supported by the CIHR Postdoctoral Fellowship [201511MFE358449-223266]. 
The role of medical students' training and community placement as a tool to enhance medical education in Canada

\begin{abstract}
We are currently witnessing unprecedented crises on an international scale linked to synthetic opioid overdose fatalities. While most governments and health policy makers have focused mainly on combating the current crises through harm reduction strategies, little focus has been given to the role and training of future doctors in evidence-based practices of harm reduction and addiction medicine. Therefore, enhancing medical student's training in the implementation of addiction medicine, and the establishment (or expansion) of medical students, residents and postfellows' community placement—via partnerships with organizations that provide specialized care to patients struggling with mental health and addiction — would strongly improve the health and well-being of marginalized populations.
\end{abstract}




\section{The role of medical students' training and community placement as a tool to enhance medical education in Canada}

\section{Background}

In 2016 alone, overdose mortalities in both Canada or the United States (U.S.) linked to the introduction of synthetic opioids such as fentanyl into the illegal drug market have now surpassed the total number of U.S. soldiers killed during the Vietnam war (Duggan, 2017; Jarrett, 2017; Wood, 2018). Most jurisdictions and local health authorities in Canada have implemented various methods to contain the current drug overdose epidemic, such as free naloxone distribution, public awareness campaigns, and overdose prevention sites (Thomson, Lampkin, Maynard, Karamouzian, \& Jozaghi, 2017). The province of British Columbia (B.C.), being one of the first and hardest hit provinces, has also established holistic drop-in-centers in Vancouver for mental health and addiction (Jozaghi \& Bird, 2018). In addition, it is the only North American city to provide hydromorphone-assisted programs to small groups of patients (e.g., 300 patients) (Jozaghi \& Dadakhah-Chimeh, 2018; Thomson et al., 2017). The majority of funding and the focus of health authorities and government policy makers has been directed toward preventing overdose mortalities (Jozaghi \& Dadakhah-Chimeh, 2018).

However, there has been scant attention being drawn toward the role of physicians in evidencebased harm reduction and addiction medicine and their contributions to the management and prevention of the current overdose crisis (Van Boekel, Brouwers, Van Weeghel, \& Garretsen, 2013). Previous studies have highlighted the effects of negative stigmas and attitudes of health professionals toward people who use illegal drugs, subsequently resulting in detrimental consequences for a patient's diagnosis, treatment, and recovery (Ball, Carroll, Canning-Ball, \& Rounsaville, 2006; Jozaghi \& Dadakhah-Chimeh, 2018; Neale, Tompkins, \& Sheard, 2008).

\section{Skill deficits of physicians}

The negative attitude and stigmatizing behaviors toward people who use illegal drugs by medical practitioners, specifically physicians, have been linked to a lack of knowledge and clinical experience which in turn not only diminishes the quality of care but also decreases the likelihood of patients to seek adequate health care (Ball et al., 2006; Eaton, 2004; Neale et al., 2008). It is not surprising that over the past few years the global burden of addiction and mental health costs have increased substantially, and that many people who use drugs (PWUDs) drop out of care before their course of treatment has been fully completed (Eaton, 2004; Whiteford et al., 2013). While opioid addiction fulfills the criteria of a chronic illness such as diabetes, it is not very difficult to treat when compared to other chronic 'lifestyle diseases' (Martyres, Clode, \& Burns, 2004; Mertens, Weisner, Ray, Fireman, \& Walsh, 2005). Granting its increasingly prevalence in the health-care settings, routine screening and treatment for opioid addiction remains far below other chronic illnesses, giving the health-care professionals the perception of its challenging nature (Martyres et al., 2004; Mertens et al., 2005). 
There is growing recognition in Canada and abroad for the need to improve the skills and practices of physicians when dealing with patients who may have unhealthy substance use and addiction issues (Hering, Lefebvre, Stewart, \& Selby, 2014; O'Connor et al., 2017). For example, the creation of the examination for the American Board of Addiction Medicine, the certification for the Canadian Society of Addiction Medicine, and more than 37 addiction medicine fellowship programs are some of the ways that health policy makers have attempted to address current health-care crisis (Kunz \& Wiegand, 2016). However, there is still an urgent need for an increase in the number of trained physicians to meet the current demands of PWUDs (Hering et al., 2014; Kunz \& Wiegand, 2016; O'Connor et al., 2017).

\section{Training/education of medical students, residents, and post-fellows}

Addiction medicine is an important medical specialty in a multidisciplinary field that enhances the processes of screening, diagnosis, treatment, education, and advocacy (Polydorou, Gunderson, \& Levin, 2008). There is growing acknowledgment and awareness amongst institutions concerning a lack of sufficient substance use and addiction medicine curriculum in undergraduate medical programs (Polydorou et al., 2008). Furthermore, there is an increase in the mutual understanding that graduating residents should demonstrate necessary competency in managing substance abuse cases (Polydorou et al., 2008). Polydorou et al. (2008) recommend expanding the curriculum for medical residents, emphasizing the connection of addiction medicine with qualified faculty, improving the coordination of scheduling amongst different branches in the medical faculty, and most importantly, increasing clinical exposure via harm reduction and addiction medicine training. Due to the extensive evidence surrounding the reluctance of many PWUDs to seek medical help from primary health-care providers - due to stigma, inadequate access, lack of transportation, and homelessness (Jozaghi \& Marsh, 2017) there is a need for medical schools to have required clinical placements within community organizations that provide on-the-ground social services. This will not only enhance the clinical experience of physicians but also improve the health care experiences of PWUDs. This is especially relevant, as historical trends reveal that PWUDs have obtained a majority of their health-care needs via supervised injection facilities or peer-based networks (Bouchard, Hashimi, Tsai, Lampkin, \& Jozaghi, 2018; Jozaghi, 2015a; Tyndall et al., 2006).

There is also growing evidence of the effectiveness of peer-based models of public health initiatives (Jozaghi, Greer, Lampkin, \& Buxton, 2018). These include the Vancouver Area Network of Drug Users, the Western Aboriginal Harm Reduction Society, the British Columbia Association for People on Methadone, the Eastside Illicit Drinkers Group for Education, the SALOME/NAOMI Association of Patients, community clinics, detox centers, overdose prevention sites, and the highly beneficial outcome of networks and partnerships between public health providers who provide specialized care to patients struggling with poverty, mental health, and addiction (Bouchard et al., 2018; Goodman et al., 2017; Jozaghi, 2015b, 2014; Jozaghi et al., 2018). 


\section{Conclusion}

The economic cost of untreated substance abuse and addiction- related illnesses has now surpassed cancer and diabetes combined; however, there continues to be a vast shortage of addiction physicians in the health-care system (Hering et al., 2014; Kunz \& Wiegand, 2016). In fact, very few physicians practice addiction medicine on a full-time basis, and a large deficit in knowledge of evidence-based addiction medicine and harm reduction models among medical residents and general practitioners have contributed to the negative stigma of PWUDs when accessing care (Kunz \& Wiegand, 2016; Polydorou et al., 2008). This has been especially detrimental for Indigenous patients with substance abuse needs (Jozaghi \& Dadakhah-Chimeh, 2018). These individuals have been the most significantly impacted cultural group to suffer from health-care discrimination, as well as from a lack of cultural knowledge and consideration by primary health-care providers (Evans, White, \& Berg, 2014; Goodman et al., 2017).

There have been several important developments in recent years, such as the research fellowship in Addiction Medicine, the St. Paul's Hospital Goldcorp Addiction Medicine Fellowship, the establishment of new clinics that are tailored to the needs of Indigenous patients, a new federally sponsored initiative to build collaborations in Addiction research, and the application for the first Canadian certification in Addiction Medicine (Hering et al., 2014; Klimas et al., 2017; O'Connor, 2018). However, the training of the next generation of physicians cannot be successfully completed and practiced unless medical schools can effectively facilitate a partnership with drugusing communities. Therefore, enhancing the community placement of medical students and residents will greatly improve the health and well-being of marginalized populations. 


\section{Letter to the editor}

\section{References}

Ball, S. A., Carroll, K. M., Canning-Ball, M., \& Rounsaville, B. J. (2006). Reasons for dropout from drug abuse treatment: Symptoms, personality, and motivation. Addictive Behaviors, 31(2), 320-330. doi:10.1016/j.addbeh.2005.05.013

Bouchard, M., Hashimi, S., Tsai, K., Lampkin, H., \& Jozaghi, E. (2018). Back to the core: A network approach to bolster harm reduction among persons who inject drugs. International Journal of Drug Policy, 51, 95-104. doi:10.1016/j.drugpo.2017.10.006

Duggan, K. (2017). Canada's opioid crisis could kill more than 4,000 this year, say officials. Published 2017. Retrieved December 20, 2017, from https://ipolitics.ca/2017/12/18/canadas-opioid-crisis-kill-4000-year-say-officials/

Eaton, L. (2004). Numbers starting treatment for drug misuse increase by $20 \%$ over two years. BMJ: British Medical Journal, 329(7474), 1066. doi:10.1136/bmj.329.7474.1066-e

Evans, M., White, K., \& Berg, L. (2014). They think you're lying about your need": the impact of appearances on health and social service access for aboriginal people in Canada. The Canadian Journal of Native Studies, 34(1), 55.

Goodman, A., Fleming, K., Markwick, N., Morrison, T., Lagimodiere, L., \& Kerr, T. (2017). "They treated me like crap and I know it was because I was Native": The healthcare experiences of Aboriginal peoples living in Vancouver's inner city. Social Science \& Medicine, 178, 87-94. doi:10.1016/j.socscimed.2017.01.053

Hering, R. D., Lefebvre, L. G., Stewart, P. A., \& Selby, P. L. (2014). Increasing addiction medicine capacity in Canada: The case for collaboration in education and research. Canadian Journal of Addiction, 5(3), 10-14.

Jarrett, M. P. (2017). Congress, take an Ebola inspired approach to the opioid epidemic. Retrieved December 20, 2017, from http://thehill.com/blogs/pundits-blog/healthcare/339509-congress-take-an-ebolainspired-approach-to-the-opioid-epidemic

Jozaghi, E.; Vancouver Area Network of Drug Users. (2014). A cost-benefit/cost-effectiveness analysis of an unsanctioned supervised smoking facility in the Downtown Eastside of Vancouver, Canada. Harm Reduction Journal, 11(1), 1-9. doi:10.1186/1477-7517-11-1

Jozaghi, E. (2015a). The role of peer drug users' social networks and harm reduction programs in changing the dynamics of life for people who use drugs in the downtown eastside of Vancouver, Canada. (Doctoral dissertation). Simon Fraser University.

Jozaghi, E., \& Vancouver Area Network of Drug Users. (2015b). Exploring the role of an unsanctioned, supervised peer driven injection facility in reducing HIV and hepatitis C infections in people that require assistance during injection. Health \& Justice, 3(1), 1-10. doi:10.1186/s40352-015-0028-0

Jozaghi, E., \& Bird, L. (2018). A plea for harm reduction policing involving people who use drugs. International Journal of Health Policy and Management, in press. doi:10.15171/ijhpm.2018.29

Jozaghi, E., \& Dadakhah-Chimeh, Z. (2018). A call for action to combat the growing synthetic opioid epidemic: The need for the creation and expansion of addiction and psychiatric nursing programs. Journal of School of Nursing, 34(1), 11-13. doi: $10.1177 / 1059840517746729$

Jozaghi, E., Greer, A. M., Lampkin, H., \& Buxton, J. A. (2018). Activism and scientific research: 20 years of community action by the Vancouver area network of drug users. Substance Abuse Treatment, Prevention, and Policy, in press. doi: 10.1186/s13011-018-0158-1

Jozaghi, E., \& Marsh, S. (2017). Missing the trends in the fentanyl overdose crisis: The need for immediate intervention in small and rural communities. Canadian Journal Public Health, 108(4), 457. doi:10.17269/cjph.108.6480

Klimas, J., McNeil, R., Ahamad, K., Mead, A., Rieb, L., Cullen, W., ...Small, W. (2017). Two birds with one stone: Experiences of combining clinical and research training in addiction medicine. BMC Medical Education, 17(1), 22. doi:10.1186/s12909-017-0929-9

Kunz, K., \& Wiegand, T. (2016). Addiction medicine: Current status of certification, maintenance of certification, training, and practice. Journal of Medical Toxicology, 12(1), 76-78. doi:10.1007/s13181-015-0524-6

Martyres, R. F., Clode, D., \& Burns, J. M. (2004). Seeking drugs or seeking help? Escalating" doctor shopping" by young heroin users before fatal overdose. Medical Journal of Australia, 180(5), 211.

Mertens, J. R., Weisner, C., Ray, G. T., Fireman, B.,\&Walsh, K. (2005). Hazardous drinkers and drug users in HMO primary care: Prevalence, medical conditions, and costs. Alcoholism: Clinical and Experimental Research, 29(6), 989-998. doi:10.1097/01. ALC.0000167958.68586.3D

Neale, J., Tompkins, C., \& Sheard, L. (2008). Barriers to accessing generic health and social care services: A qualitative study of injecting drug users. Health \& Social Care in the Community, 16(2), 147-154. doi:10.1111/j.1365-2524.2007.00739.x 


\section{Letter to the editor}

O'Connor, N. (2018). VCH healthcare opens a new clinic in Vancouver Downtown Eastside. Richmond News. Retrieved January 25, 2018, from http://www.richmond-news.com/vch-healthcare-opens-a-newclinic-in-vancouver-downtown-eastside-1.23152089

O'Connor, P., Tsui, J. I., Gobel, D., Brett, B., Bridden, C., \& Samet, J. H. (2017). The research in addiction medicine scholars program-developing researchers in addiction fellowships. Drug \& Alcohol Dependence, 171, e154.doi:10.1016/j.drugalcdep.2016.08.425

Polydorou, S., Gunderson, E. W., \& Levin, F. R. (2008). Training physicians to treat substance use disorders. Current Psychiatry Reports, 10(5), 399-404.

Thomson, E., Lampkin, H., Maynard, R., Karamouzian, M., \& Jozaghi, E. (2017). The lessons learned from the fentanyl overdose crises in British Columbia, Canada. Addiction, 112(11), 2068-2070. doi:10.1111/add.13961

Tyndall, M. W., Kerr, T., Zhang, R., King, E., Montaner, J. G., \& Wood, E. (2006). Attendance, drug use patterns, and referrals made from North America's first supervised injection facility. Drug \& Alcohol Dependence, 83(3), 193-198.

doi:10.1016/j.drugalcdep.2005.11.011

Van Boekel, L. C., Brouwers, E. P., Van Weeghel, J., \& Garretsen, H. F. (2013). Stigma among health professionals towards patients with substance use disorders and its consequences for healthcare delivery: Systematic review. Drug \& Alcohol Dependence, 131(1), 2335.doi:10.1016/j.drugalcdep.2013.02.018

Whiteford, H. A., Degenhardt, L., Rehm, J., Baxter, A. J., Ferrari, A. J., Erskine, H. E., ... Burstein, R. (2013). Global burden of disease attributable to mental and substance use disorders: Findings from the Global Burden of Disease Study 2010. The Lancet, 382(9904), 1575-1586. doi:10.1016/S0140-6736(13)61611-6

Wood, E. (2018). Strategies for reducing opioid-overdose deaths-lessons from Canada. New England Journal of Medicine, 378(17), 1565-1567. doi: 10.1056/NEJMp1800216 